\title{
Caracterização biológica, histopatológica e análise de ácido nucléico de uma cepa Trypanosoma cruzi da região de Marilia, SP
}

\author{
Biological and histopathological characterization together with nucleic acids \\ analysis of a Trypanosoma cruzi strain from Marilia, São Paulo State \\ Luciamáre Perinetti Alves Martins', Roberto Esteves Pires Castanho', João Aristeu da Rosa², \\ Luiz Carlos da Silva ${ }^{3}$, Charles Antônio Pires de Godoy'1 e Raphael de Maurício Rosa1
}

\begin{abstract}
Resumo Estudou-se o comportamento biológico e histopatológico de uma cepa genuínamente mariliense de Trypanosoma cruzi, isolada em 1997 através de xenodiagnóstico artificial. Vinte e cinco camundongos swiss foram infectados intraperitonealmente, sendo 11 utilizados para a realização da curva parasitêmica e observação da morfologia dos tripomastigotas e 14 foram sacrificados após o 17, 23, 30, 60 e 180 dias pós-infecção e coletados coração, esôfago, fígado, cólon, e músculo esquelético (fragmento da coxa direita) para análise histopatológica. Cultura em meio LIT foi realizada para análise de DNA. Os resultados mostraram predomínio de formas largas, baixa parasitemia com picos médios de 860 tripomastigotas $/ 5 \mu$ l de sangue ao redor do $20^{\circ}$ dia de infecção. Nenhum camundongo morreu na fase aguda da infecção. Exame histopatológico mostrou poucos ninhos de amastigotas em coração, raros em músculo esquelético e cólon com discreto processo inflamatório. Comparada com a cepa Y, que foi isolada de uma paciente da mesma região, notamos diferentes características biológicas e comportamentais, porém a análise de DNA as coloca no mesmo grupo, demonstrando a proximidade dessas cepas.
\end{abstract}

Palavras-chaves: Trypanosoma cruzi. DNA. Histopatológico. Cepa Famema. Infecção experimental.

Abstract The aim of this report was to study the biological and histopathological behavior of a Trypanosoma cruzi strain, which is found in the region of Marilia. The strain was isolated in 1997, by artificial xenodiagnosis. Twenty-five swiss mice were intraperitoneally inoculated. Eleven were used for observation of parasitemia and trypomastigotes morphology and 14 were sacrificed after 17, 23, 30, 60 and 180 days post-infection. Heart, esophagus, liver, colon, and skeletal muscle (fragment of the right thigh) were collected for histopathological study. LIT culture medium was accomplished for DNA analysis. The results showed predominance of broad forms, low parasitemia with mean peaks of 860 trypomastigotes $/ 5 \mu /$ of blood of the $20^{\text {th }}$ day of infection. No animal died in the acute phase of infection. Histopathological analysis showed several pseudocysts of amastigotes in heart, rare in skeletal muscle and colon with discreet inflammatory process. When Famema strain was compared with $Y$ strain, which was isolated from a patient who lived in the same area, a distinct behaviour and biological characteristics were observed. However, DNA analysis placed them in same group, hence displaying the proximity of these strains.

Key-words: Trypanosoma cruzi. DNA. Histopathological. Famema strain. Experimental infection.

Estima-se que 16 a 18 milhões de pessoas estejam infectadas pela doença de Chagas atingindo cerca de 17 países do continente americano ${ }^{13}$, causando danos sociais extremamente graves ${ }^{7}$.

As diversas manifestações clínicas observadas na doença de Chagas passam por períodos ou fases, algumas relacionadas ao hospedeiro como a resposta imune, e outras inerentes ao parasita que apresenta distintas características evidenciadas pela diversidade de cepas isoladas dos mais diferentes hospedeiros ${ }^{3}$.

Andrade ${ }^{1}$, estudando vários parâmetros biológicos e histopatológicos das cepas de Trypanosoma cruziem camundongos swiss, classificou-as em 3 tipos ou biodemas. Em 1997, Andrade \& Magalhães ${ }^{2}$, realizando estudo biológico e isoenzimático, confirmaram a relação existente entre os biodemas e zimodemas das cepas

1.Disciplina de Parasitologia da Faculdade de Medicina de Marília.2. Disciplina de Parasitologia da Faculdade de Ciências Farmacêuticas da Universidade Estadual Paulista Júlio de Mesquita Filho, Araraquara, SP. 3. Disciplina de Anatomia Patológica da Faculdade de Medicina de Marília, Marília, SP. Endereço para correspondência: Dra. Luciamare P.A. Martins. Av. Monte Carmelo 800, 17519-030 Marília,SP.

Tel: 5514 421-1764, Fax: 5514 423-4781

e-mail: luciapam@famema.br

Recebido para publicação em 26/11/2001. 
de Trypanosoma cruzi encontradas em diferentes regiões geográficas.

É provável que essas diferenças comportamentais tanto biológicas como clínicas estejam na verdade relacionadas à heterogeneidade das subpopulações das cepas de T. cruzi observadas no estudo dos clones ${ }^{35}$.

Vários autores ${ }^{8} 161720$ estudando a porção do DNA que codifica o gene 24 S $\alpha$ RNA ribossomal e a seqüência do gene mini-exon de cepas e clones de $T$. cruzi oriundas de diversas regiões do continente americano, propuseram uma divisão do T. cruzi em 2 grupos principais, os quais apresentam uma alta divergência filogenética. Baseado nesses estudos, aceita-se hoje a divisão das cepas de T. cruzi em $T$. cruzi I, cepas que predominam no ambiente silvestre e T. cruzi II, as que predominam no ambiente doméstico.
Martins et $\mathrm{al}^{12}$ tendo isolado uma cepa de T. cruzi, que foi denominada cepa Famema, observaram que a mesma apresentava baixa parasitemia, com picos de 3.000 a 5.000 formas $/ 5 \mu$ l de sangue no $20^{\circ}$ dia da infecção e baixa virulência, não havendo óbito de nenhum dos animais infectados e com predomínio de formas largas na fase aguda da infecção. Esses dados permitiram incluí-la teoricamente no biodema II de Andrade ${ }^{1}$ e por analogia, no zimodema Z2 de Andrade \& Magalhães ${ }^{2}$, embora mais estudos se fizessem necessários para melhor caracterizá-la.

Visto que a cepa Famema é oriunda da mesma região da cepa $\mathrm{Y}$ (Marília-SP) e apresenta comportamento biológico bastante diferente, optou-se por caracteriza-la biológica e histopatológicamente.

\section{MATERIAL E MÉTODOS}

A cepa Famema de T. cruzi foi isolada em 1997, por xenodiagnóstico artificial, segundo a técnica de Lima \& Rey ${ }^{14}$, de um paciente com 57 anos de idade, assintomático, nascido e crescido na região de Marília,SP. Desde então é mantida por repiques sucessivos em camundongos swiss.

Caracterização biológica. Curva parasitêmica: onze camundongos swiss de 20 dias de idade, pesando em média $10 \mathrm{~g}$ foram inoculados intraperitonealmente com aproximadamente 17.000 formas de T. cruzi, provenientes de outro camundongo previamente infectado. Após o $4^{\circ}$ dia da infecção, $5 \mu$ l de sangue obtido da cauda foi examinado ao microscópio para contagem das formas seguindo a técnica de Brener ${ }^{4}$. A contagem foi realizada em dias alternados até o 70 dia.

Aspectos morfológicos: para observação das formas tripomastigotas, foi coletado o sangue total em seringa heparinizada, através de punção cardíaca. O sangue total foi centrifugado, realizando-se esfregaço com o creme leucocitário em lâmina, as quais foram coradas pelo método de Giemsa.
Análise histopatológica. Quinze camundongos swiss, com as mesmas características dos citados acima, foram divididos em 4 lotes, e sacrificados para pesquisa de ninhos de amastigotas. Foram coletados coração, esôfago, fígado, colon e músculo esquelético (fragmento de coxa direita) do seguinte modo:

lote 1-3 camundongos $(A, B, C)$ sacrificados no $17^{\circ}$ dia pós infecção

lote 2 : 3 camundongos $(A, B, C)$ sacrificados no $23^{\circ}$ dia pós infecção

lote 3 : 3 camundongos $(A, B, C)$ sacrificados no $30^{\circ}$ dia pós infecção

lote 4 : 3 camundongos $(A, B, C)$ sacrificados no $60^{\circ}$ dia pós infecção

lote 5: 2 camundongos (A, B) sacrificados no $180^{\circ}$ dia pós infecção

Os tecidos foram incluídos em parafina e as seções de $5 \mu \mathrm{m}$ coradas pela hematoxilina-eosina e analisadas em microscópio óptico.

Análise de DNA. A análise do DNA foi realizada por reação de PCR seguindo a técnica de Souto \& Zingales ${ }^{17}$.

\section{RESULTADOS}

A cepa Famema apresenta como característica parasitemia e virulência baixas, que podem ser observadas analisando a curva média (Figura 1) obtida com a leitura de $5 \mathrm{ml}$ de sangue dos onze camundongos infectados. No $4^{\circ}$ dia pós-infecção já se observam as primeiras formas no sangue circulante, que vão aumentando gradativamente, atingindo o pico da parasitemia ao redor do $20^{\circ}$ dia, com uma média de 860 tripomastigotas em $5 \mu l$ de sangue. Após esse período, os tripomastigotas sangüíneos vão diminuindo, desaparecendo da corrente sangüínea ao redor do $70^{\circ}$ dia. Durante esse período não se observou morte dos camundongos.

A morfologia dos tripomastigotas foi observada no período de pico da parasitemia com predomínio de formas largas.
Os ninhos de amastigotas em quantidade moderada ou rara, acompanhados de discreto processo inflamatório foram encontrados principalmente no coração de sete animais examinados. Parasitismo discreto foi observado em músculo esquelético de dois camundongos e em um na musculatura lisa do cólon (Tabela 1). Observouse principalmente no miocárdio, a persistência do processo inflamatório mesmo com a ausência do parasita.

Análise do DNA através da reação de amplificação por PCR classificou a cepa Famema como pertencente ao mesmo grupo da cepa CL Brener, ou seja, ao grupo T. cruzill. 




Figura 1 - Curva média realizada com a leitura da parasitemia dos 11 camundongos estudados.

Tabela 1 - Análise histopatológica.

\begin{tabular}{|c|c|c|c|c|c|c|}
\hline \multirow[b]{2}{*}{ Lotes } & \multirow[b]{2}{*}{ Animais } & \multicolumn{5}{|c|}{ Histopatológico } \\
\hline & & coração & $\begin{array}{l}\text { músculo } \\
\text { esquelético }\end{array}$ & cólon & esôfago & fígado \\
\hline \multirow{3}{*}{ Lote 1} & $1 \mathrm{~A}$ & ++ & + & - & - & - \\
\hline & $1 \mathrm{~B}$ & - & - & - & - & - \\
\hline & $1 \mathrm{C}$ & ++ & - & - & - & - \\
\hline \multirow{3}{*}{ Lote 2} & $2 \mathrm{~A}$ & ++ & - & - & - & - \\
\hline & $2 B$ & ++ & - & - & - & - \\
\hline & $2 \mathrm{C}$ & + & - & - & - & - \\
\hline \multirow{3}{*}{ Lote 3} & $3 A$ & + & - & - & - & - \\
\hline & 3B & - & - & - & - & - \\
\hline & $3 C$ & ++ & - & ++ & - & - \\
\hline \multirow{3}{*}{ Lote 4} & $4 \mathrm{~A}$ & - & - & - & - & - \\
\hline & 4B & - & + & - & - & - \\
\hline & $4 \mathrm{C}$ & - & - & - & - & - \\
\hline \multirow{3}{*}{ Lote 5} & $5 \mathrm{~A}$ & - & - & - & - & - \\
\hline & $5 \mathrm{~B}$ & - & - & - & - & - \\
\hline & - & - & - & - & - & - \\
\hline
\end{tabular}

++ moderado + raro - ausente

\section{DISCUSSÃO}

A cepa Famema é genuinamente mariliense e foi isolada em 1997 por xenodiagnóstico artificial de um paciente que nasceu e cresceu em uma fazenda próxima à Marília-SP, cidade onde mora até hoje, que localiza-se no centro-oeste paulista, região tida como área endêmica da doença de Chagas.

Estudos preliminares realizados por Martins et al ${ }^{12}$ com a cepa Famema, mostraram a baixa parasitemia e virulência da mesma para camundongos swiss, com picos parasitêmicos ao redor do 20 ㅇa pós infecção, apresentando uma média de 4.300 tripomastigotas em $5 \mathrm{ml}$ de sangue e predomínio de formas largas na fase aguda da infecção. Os resultados atuais, após três anos de repiques sucessivos em camundongos mostram esse mesmo comportamento dos estudos preliminares, notando-se apenas uma diminuição na parasitemia, com uma média de 860 tripomastigotas em $5 \mu$ lde sangue.

O estudo das alterações anatomopatológicos induzidas pela cepa Famema, mostrou miotropismo com envolvimento predominante de miocárdio, tanto é que dos nove animais examinados no pico da fase aguda (até o 30 dia), sete apresentavam presença de parasitismo em células musculares cardíacas. Da mesma forma, dos animais analisados, dois mostraram parasitismo em músculo esquelético e um na 
musculatura lisa do cólon. No esôfago e fígado não foram observados parasitismo celular. Por outro lado, durante todo o curso da infecção notou-se o predomínio das formas largas de tripomastigotas sanguíneos.

Como se sabe, em 1950, Silva \& Nussenzweig ${ }^{15}$, isolaram a cepa $Y$, de uma paciente que se encontrava na fase aguda da doença de Chagas, que residia na região de Marília. Essa cepa no início de seu isolamento apresentava baixa virulência para camundongos e após 2 anos de repiques sucessivos para manutenção, teve sua virulência acentuada, sendo a responsável pela morte de praticamente $100 \%$ dos animais infectados. Em 1975, Takeda et $\mathrm{al}^{18}$ realizaram um xenodiagnóstico nessa mesma paciente, reisolando a cepa, denominando-aYr. Essa cepa apresentou-se com baixa virulência para camundongos swiss, baixa parasitemia e baixo índice de parasitismo tissular, características essas que se mantiveram por repiques sucessivos durante 3 anos de observações.

Aspectos bastante semelhantes da cepa Famema foram observadas na cepa Yr, que apresentava predomínio de formas intermediárias e parasitismo em musculatura cardíaca e esquelética na fase aguda. Enquanto com a cepa Y, nota-se o predomínio de formas delgadas e macrofagotropismo na fase aguda da infecção ${ }^{1}$.

Considerando-se os parâmetros utilizados por Andrade ${ }^{1}$ para caracterizar as cepas de T. cruziem 3 tipos ou biodemas, onde a cepa Y foi classificada como tipo I, poderíamos enquadrar a cepa Famema como tipo II. Em 1997, Andrade \& Magalhães ${ }^{2}$ correlacionaram os biodemas com os zimodemas, observando a presença do mesmo tipo e zimodema em uma determinada região geográfica, aspectos esses que caracterizam as manifestações clínico patológicas da doença de Chagas em diferentes regiões. Tibayrenc \& Ayala ${ }^{19}$ também observaram a presença de um mesmo zimodema em uma mesma região geográfica, relacionando a provável influência do meio ambiente e local de adaptação.

Recentemente, com base na análise da porção que codifica o gene 24S $\alpha$ RNA e a seqüência do gene miniexon através da reação de PCR, as cepas de T. cruzi foram divididas em 2 grandes grupos, ou seja, grupo T. cruzi I cepas que amplificam 110 pb para o rDNA e $350 \mathrm{pb}$ para o mini-exon, predominantes no ambiente silvestre e o grupo T. cruzi II, cepas que amplificam $125 \mathrm{pb}$ no rDNA e 300pb para o mini-exon que predominam no ambiente doméstico.

A análise do DNA da cepa Famema, a enquadra no grupo T. cruzi II, o mesmo grupo da cepa $Y$, apesar das mesmas apresentarem diferenças comportamentais distintas na infecção experimental em camundongos, e assim pertencerem a biodemas diferentes. Entendemos que mesmo sem uma confirmação pela análise isoenzimática da cepa Famema, podemos observar uma concordância do DNA que codifica o RNA ribossomal entre as duas cepas, o que provavelmente, colocaria nossa cepa recentemente isolada no zimodema Z2, zimodema este relacionado ao da cepa Y, ou seja, Z2b, variante do Z2. De qualquer forma é importante ressaltar a procedência de ambas as cepas, ou seja, isoladas de indivíduos moradores em uma mesma zona endêmica. Chama a atenção ainda o fato da cepa $\mathrm{Yr}$ ter apresentado, pelo menos em análises preliminares, comportamento mais parecido com a cepa Famema do que com a cepa $Y$ isolada por Silva \& Nussenzweig ${ }^{15}$.

Transformações no comportamento biológico das cepas de $T$. cruzi podem ocorrer durante a realização de repiques sucessivos em camundongos, onde as condições de manutenção do laboratório agiriam como meio selecionador 6 . Fato semelhante pôde ser observado na obtenção de clones dessas cepas, onde além das condições de manutenção, o meio de cultura também atuaria como seletivo ${ }^{10}$. Goldberg \& Pereira da Silva ${ }^{9}$ encontraram em 18 subclones da cepa $Y$ padrões isoenzimáticos semelhantes à cepa parental e Tanuri et al, citado por Gomes et $a^{10}$, observaram variações isoenzimáticos em 3 clones da mesma cepa utilizando meio de cultura diferente. Para Macedo \& Pena ${ }^{11}$, os clones representam uma linhagem que se reproduz por divisão binária e permanece inalterada por várias gerações até que ocorram as mutações.

Ao que parece os vários aspectos biológicos e morfológicos das cepas de T. cruzi podem estar na dependência de vários fatores, inclusive os hospedeiros que podem funcionar como um meio seletivo, e em se tratando de seres de divisão assexuada, poderíamos dizer que as cepas de T.cruzisão frutos de clones selecionados em função de diferentes variantes que se pode encontrar numa relação parasita-hospedeiro-ambiente.

\section{AGRADECIMENTOS}

À Profa. Dra. Bianca Zingales do Instituto de Química da Universidade de São Paulo pela realização e análise da reação de PCR.

\section{REFERÊNCIAS BIBLIOGRÁFICAS}

1. Andrade SG. Morphological and behavioural characterization of Trypanosoma cruzi strains. Revista da Sociedade Brasileira de Medicina Tropical 18(supl):39-46, 1985.

2. Andrade SG, Magalhães JB. Biodemes and zymodemes of Trypanosoma cruzi strains: correlations with clinical data and experimental pathology. Revista da Sociedade de Medicina Tropical 31:27-35, 1997.
3. Araújo SM, Chiari E. Caracterização biológica de clones das cepas $\mathrm{Y}, \mathrm{CL}$ e MR de Trypanosoma cruzi em camundongos $\mathrm{C}_{3} \mathrm{H}$ isogênicos. Memórias do Instituto Oswaldo Cruz 83:175-181, 1988.

4. Brener Z. Therapeutic activity and criterion of cure on mice experimentally infected with Trypanosoma cruzi. Revista do Instituto de Medicina Tropical de São Paulo 4: 389-396, 1962. 
5. Camandaroba ELP, Campos RF, Magalhães JB, Andrade SG. Clonal structure of Trypanosoma cruzi Colombian strain (biodeme Type III): biological, isoenzymic and histopathological analysis of seven isolated clones. Revista da Sociedade Brasileira de Medicina Tropical 34: 151-157, 2001.

6- Carneiro M, Romanha AJ, Chiari E. Biological characterization of Trypanosoma cruzi strains from different zymodemes and schizodemes. Memórias do Instituto Oswaldo Cruz 86: 387-393, 1991.

7- Dias JCP, Schofield CJ. Controle da transmissão transfusional da doença de Chagas na Iniciativa do Cone Sul. Revista da Sociedade de Medicina Tropical 31: 373-383, 1998.

8- Fernandes O, Santos SS, Junqueira ACV, Jansen AM, Cupolillo E, Campbell DA, Zingales B, Coura JR. Populational heterogeneity of Brazilian Trypanosoma cruzi isolates revealed by the miniexon and ribosomal spacers. Memórias do Instituto Oswaldo Cruz 94(supl):195-197, 1999.

9- Goldberg SS, Silva Pereira AA. Enzyme variation among clones of Trypanosoma cruzi. Journal of Protozoology 69: 91-96, 1983.

10. Gomes ML, Romanha AJ, Gonçalves AM, Chiari E. Stability of isoenzyme and kinetoplast DNA (K-DNA) patterns in successively cloned Trypanosoma cruzi populations. Memórias do Instituto Oswaldo Cruz 86: 379-385, 1991.

11. Macedo AM, Pena SDJ. Genetic Variability of Trypanosoma cruzi: implications for the pathogenesis of Chagas disease. Parasitology Today 14:119-123, 1998.
12. Martins LPA, Castanho REP, Turine CA. Caracterização de uma cepa de Trypanosoma cruzi isolada na faculdade de Medicina de Marília. The Brazilian Journal of Infections Diseases 3 (supl 2):595, 1999.

13. Organização Mundial de Saúde. Control de la Enfermedad de Chagas. Ginebra, 1991.

14. Rey L. Parasitologia. Guanabara Koogan, Rio de janeiro, 1991.

15. Silva LHP, Nussenzweig V. Sobre uma cepa de Trypanosoma cruzi altamente virulenta para o camundongo branco. Folia Clínica et Biológica 20:191-208, 1953.

16. Souto RP, Fernandes O, Macedo AM, Campbell DA, Zingales B. DNA markers define two major phylogenetic lineages of Trypanosoma cruzi. Molecular and Biochemical Parasitology 83:141-152, 1996.

17. Souto RP, Zingales B, Sensitive detection and strain classification of Trypanosoma cruzi by amplification of a ribosomal RNA sequences. Molecular and Biochemical Parasitology 62:45-52, 1993.

18. Takeda GKF, Chiari L, Campos CAM. Alguns caracteres biológicos da cepa Yr de Trypanosoma cruzi. In: Resumos do V Congresso Brasileiro de Parasitologia, Rio de Janeiro p.15, 1980.

19. Tibayrenc M., Ayala FJ. Isozyme variability in Trypanosoma cruzi, the agent of Chagas' disease: genetical, taxonomical, and epidemiological significance. Evolution 42:277-292, 1988.

20. Zingales B, Stolf BS, Souto RP, Fernandes O, Briones MRS. Epidemiology, Biochemistry and Evolution of Trypanosoma cruzi lineages based on ribosomal RNA sequences. Memórias do Instituto Oswaldo Cruz 94(supl I):159-164, 1999. 